\title{
Effects of probiotic supplementation on natural killer cell function in healthy elderly individuals: a meta-analysis of randomized controlled trials
}

\author{
Qifeng Gui $\circledast^{1,2} \cdot$ Ange Wang ${ }^{1,2} \cdot$ Xinxiu Zhao ${ }^{1,2} \cdot$ Shunmei Huang ${ }^{1,2} \cdot$ Zhongju Tan $^{1,2} \cdot$ Chi Xiao $\circledast^{3} \cdot$ \\ Yunmei Yang $\mathbb{1}^{1,2}$
}

Received: 27 February 2020 / Revised: 20 May 2020 / Accepted: 26 May 2020 / Published online: 8 June 2020

(c) The Author(s), under exclusive licence to Springer Nature Limited 2020

\begin{abstract}
To evaluate evidence for the role of probiotic supplementation in enhancing natural killer (NK) cell function in healthy elderly individuals. Five electronic databases were searched, and references of included articles and eligible reviews up to December 2019, with English language and human subject restrictions, were examined. Two independent reviewers identified randomized control trials (RCTs) of probiotic supplementation influencing NK cell function in healthy elderly individuals, assessed the quality of every article, and extracted data for subsequent meta-analysis. We identified six eligible trials including 364 healthy elderly subjects. Trials were heterogeneous in study design and probiotic supplementation (including genus, strain, dose, and duration). Five trials used Lactobacillus interventions alone or in combination with Bifidobacterium. Only one trial focused on Bacillus coagulans. The duration of supplementation ranged from 3 to 12 weeks, and the doses, from $1 \times 10^{9}$ to $4 \times 10^{10}$ colony-forming units. Pooling data of eligible trials showed that probiotics significantly $(P<0.05)$ increased NK cell activity in healthy elderly individuals (standardized mean difference $=0.777,95 \%$ confidence interval: $0.187-1.366, P=0.01, I^{2}=84.6 \%$ ). Although we obtained a significant outcome, the data do not provide convincing evidence for associations between probiotic supplementation and enhancement of NK cell function, given the small final number and very large heterogeneity. More RCTs with sufficient sample sizes and long-term follow-up are needed to focus on optimal probiotic dose, species, and duration of supplementation for healthy elderly individuals.
\end{abstract}

Supplementary information The online version of this article (https:// doi.org/10.1038/s41430-020-0670-z) contains supplementary material, which is available to authorized users.

\section{Chi Xiao \\ xcier@163.com \\ $\triangle$ Yunmei Yang \\ 1194070@ziu.edu.cn}

1 Department of Geriatrics, The First Affiliated Hospital, School of Medicine, Zhejiang University, Hangzhou, Zhejiang 310003, PR China

2 Zhejiang Provincial Key Laboratory for Diagnosis and Treatment of Aging and Physic-chemical Injury Diseases, The First Affiliated Hospital, School of Medicine, Zhejiang University, Hangzhou, Zhejiang 310003, PR China

3 School of Basic Medical Sciences \& Forensic Medicine, Hangzhou Medical College, Hangzhou, Zhejiang 310053, PR China

\section{Introduction}

The global aging population is growing very rapidly, with the number of elderly individuals expected to grow by more than $60 \%$ over the next 15 years [1]. Aging is accompanied by a decline in immune efficacy [2]. The natural decline of adaptive and innate immunity over time is termed immunosenescence [3, 4], and results in increased vulnerability to infections, diminished responses to vaccination, and susceptibility to age-related systemic chronic inflammation [2, 5]. For example, in December 2019, a novel coronavirus-borne pneumonia occurred in Wuhan, PR China [6-8], and rapidly swept over the world. Studies have established that age and the associated decline in immune function are associated with the disease's severity, ICU enrollment, and mortality $[9,10]$.

Innate immunity, which represents the first line of defense against pathogens, is known to suffer from agerelated changes $[4,11]$. Natural killer (NK) cells are an important component of the innate immune system and are 
involved in the elimination of virus-infected cells and tumor cells. They also play a key role in regulating the immune response by producing chemokines and cytokines, which can activate other types of cells associated with both the adaptive and innate immune systems [12-14].

Immunosenescence is greatly influenced by the gut microbiota [15], as gut commensal bacteria influence immune development and function [16]. In this sense, probiotics-living microbes that exert beneficial health effects when administered to a host [17]—have the potential to help elderly individuals maintain immune cells and function [18] and have also been found to improve NK cell function in healthy elderly subjects $[19,20]$. A previous meta-analysis of 14 prospective controlled studies showed that probiotic supplementation in healthy elderly individuals increased NK cell activity [19]. However, this meta-analysis included several types of prospective control studies, including six before-after studies and eight randomized control trials (RCTs). Among the eight RCTs, one study focused on immunocompromised elderly subjects, one combined probiotic and prebiotics, and one used heat-killed Lactobacillus gasseri, which is not a true probiotic. Considering the study design, which included a variety of subject types and interventions, the resulting clinical heterogeneity made it difficult to draw a conclusion from the results. A more recent RCT was published in 2019 [21]; therefore, we conducted this updated systematic review with a meta-analysis of prospective RCTs to evaluate the effects of probiotics in enhancing NK cell function in healthy elderly individuals.

\section{Materials and methods}

This review was performed in accordance with the PRISMA statement [22].

\section{Search methods for study identification}

The following databases were used in the review: Medline, Embase, Web of Science, The Cochrane Library, and Google Scholar. The search included the following terms: ("Immunity", "Natural killer cell", "NK cell", or "Tumoricidal") and ("Probiotics", "Yogurt", "Lactobacillus", "Fermented milk", "Bifidobacterial", "Nissle", "VSL\#3", "HN019" or "HN001") up to December 2019. English language and human subjects were also restrictions used in the search.

We reviewed the references of the included articles and relevant reviews. In addition, we used unpublished and ongoing trials registered in the International Clinical Trials Registry Platform. We attempted to contact the study investigators for more information or data on trials.

\section{Criteria for considering studies}

This meta-analysis matched the following five criteria: (1) participants: healthy elderly ( $\geq 65$ years old), excluding adults, children, pregnant women, athletes, people under psychological stress, inpatients, and immunocompromised elderly subjects. (2) Interventions: probiotics (any strain or dose), excluding prebiotics, synbiotics, and heat-killed probiotics. (3) Comparisons: placebo control group, excluding prebiotics and synbiotics or other probiotic control groups. (4) Outcome: NK cell activity; secondary outcome: cytokines and chemokines secreted by NK cells including interferon $\gamma$ (IFN- $\gamma$ ), granulocyte macrophagocyte colony stimulating factor (GMCSF), interleukin (IL)-5, IL13, macrophage inflammatory protein-1 (MIP-1), and regulated upon activation normal $\mathrm{T}$ cell expressed and secreted factor (RANTES) [23-25]. (5) Study design: human randomized controlled study (both crossover and parallel group study), excluding observation and semirandomized studies, as well as in vitro and animal studies.

\section{Data extraction and management}

Two reviewers (GQF and WAG) independently reviewed the titles and abstracts for all retrieved literature and excluded all irrelevant studies. The same two reviewers independently evaluated eligible studies to identify analysis data based on full-text review; a third reviewer (TZJ) resolved any differences [26].

The two reviewers also independently extracted data from all selected studies using a standardized reporting form. We recorded information for both the probiotic and control groups, including the first author, publication time, region, age, study design, sample size, probiotic used (genus, strain, dose, and duration), and NK cell marker/ effect. Any disagreement between the two reviewers was resolved through discussion and a third reviewer (TZJ).

\section{Assessment of bias in included studies}

Both reviewers (GQF and WAG) independently assessed the risk of bias for each study using the "Risk of Bias" tool, following the Cochrane Handbook for Systematic Reviews of Interventions (version 6, http://handbook.cochrane.org). The third reviewer (TZJ) resolved disagreements. Bias was assessed on selection (randomization, allocation concealment), performance (blinding of participants and personnel), detection (blinding of outcome assessment), attrition (incomplete outcome data), reporting (selective reporting), and others. Each criterion was categorized as "yes" (low risk of bias), "unclear" (unclear risk of bias), or "no" (high risk of bias)." We presented our assessment of risk of bias using two summary figures: (1) a summary of bias for each 
item across all included trials, and (2) a summary of each risk of bias item for each included trial.

\section{Data synthesis and analysis}

Meta-analyses were performed by Review Manager Version 5.3 (The Cochrane Collaboration, Oxford, UK) and STATA software Version 15.1 (Stata, College Station, TX, USA). Review Manager Version 5.3 was used for assessing the risk of bias for the included trials and to prepare the risk of bias chart. All statistical analyses were conducted using STATA 15.1. For continuous outcomes, standardized mean difference (SMD) was calculated using Cohen statistics and 95\% confidence intervals (CI) for each study. Heterogeneity was examined using $I^{2}$ statistics, and we explored potential sources of heterogeneity using subgroup and sensitivity analyses. A fixed-effect model was estimated when $I^{2}$ values of less than $50 \%$ were present. Otherwise, a random effects model was estimated. Publication bias was assessed by Begg's test $(P<0.05$ was considered significant). All analyses used two-sided tests, and $P<0.05$ was considered statistically significant.

\section{Results}

\section{Description of studies}

Our search for studies involving probiotic supplementation identified 648 articles, of which 146 duplicated studies were excluded. The remaining 502 articles went through title and abstract screening, resulting in the exclusion of further 435 articles. A total of 67 articles were selected and assessed in full; 61 articles were excluded after full-text reading for the following reasons: not RCTs, participants were not elderly or their age was unknown, multiple probiotic doses were administered, the study had no placebo control group, participants were not healthy elderly, experiments were performed in vitro or using animal models, or dead probiotics were used. Finally, six articles were included in the review for meta-analysis [21, 27-31] (Fig. 1).

\section{Basic characteristics of the selected studies}

A total of 364 subjects were enrolled in the studies described in the six selected articles. Three studies were conducted in Western countries [21, 28, 31] and the remaining three in Eastern countries [27, 29, 30]. Three trials were crossover studies [27, 28, 31], whereas the others were parallel group studies $[21,29,30]$. The probiotic interventions were primarily Lactobacillus-based, either used alone (three of six studies) [27, 29, 31] or combined with Bifidobacterium (two of six studies) [21, 30], with only one study primarily using Bacillus coagulans [28]. Daily probiotic dosages ranged from $1 \times 10^{9}$ to $4 \times 10^{10}$ colonyforming units (CFU), and the duration of treatments ranged from 3 to 12 weeks. NK cell activity was reported in all studies [21, 27-31], but in one study, the assay result was processed [28], and thus excluded from our meta-analysis evaluating NK cell function. IFN- $\gamma$ was also assessed in three studies [27, 30, 31], but the methods used for its determination of were different. Only a single study reported GMCSF, MIP-1a, MIP-1b, and RANTES levels [31]; thus, we could not perform a meta-analysis of these cytokines (Table 1).

\section{Risk of bias in included studies}

The analyses associated with the quality of each study and risk of bias are described in Figs. 2 and 3. Four studies did not mention any method of randomization [21, 27-29], and all but one study mentioned a method of allocation concealment [31]. Three studies had a high risk of bias because study participants were not blinded to either the intervention or placebo groups [29-31]. In two studies, an imbalance in either the number of or reasons for missing data between experimental and control groups was observed [21, 28]. Finally, three authors did not publish all of the targeted and measured outcomes [28, 29, 31].

\section{Effects of interventions}

The result of the meta-analysis on NK cell activity is displayed in Fig. 4. The higher NK cell activity observed in the probiotic group in comparison with the control group was deemed to be statistically significant. The pooled SMD of NK cell activity was 0.777 (95\% CI: 0.187-1.366, $P=$ 0.01, random Cohen), exhibiting a significant favorable result for probiotic supplementation (Fig. 4). A significant heterogeneity in NK cell activity was found among these studies $\left(I^{2}=84.6 \%, P<0.001\right)$. Begg's test for publication bias was not evident $(P=0.806$, Fig. 5).

\section{Discussion}

In this meta-analysis of RCTs, we found evidence that supports a favorable association between probiotic supplementation in healthy elderly individuals and increasing NK cell activity. Our results are similar to those of previous meta-analysis studies [19, 20]. In 2017, Miller et al. [20] found that $B$. lactis HNO19 could enhance NK cell function in healthy elderly individuals. In 2019, another metaanalysis showed that short-term probiotic supplementation can also enhance NK cell function in healthy elderly individuals [19]. Among the cytokines and chemokines secreted 
Fig. 1 Flow diagram of the literature search process.

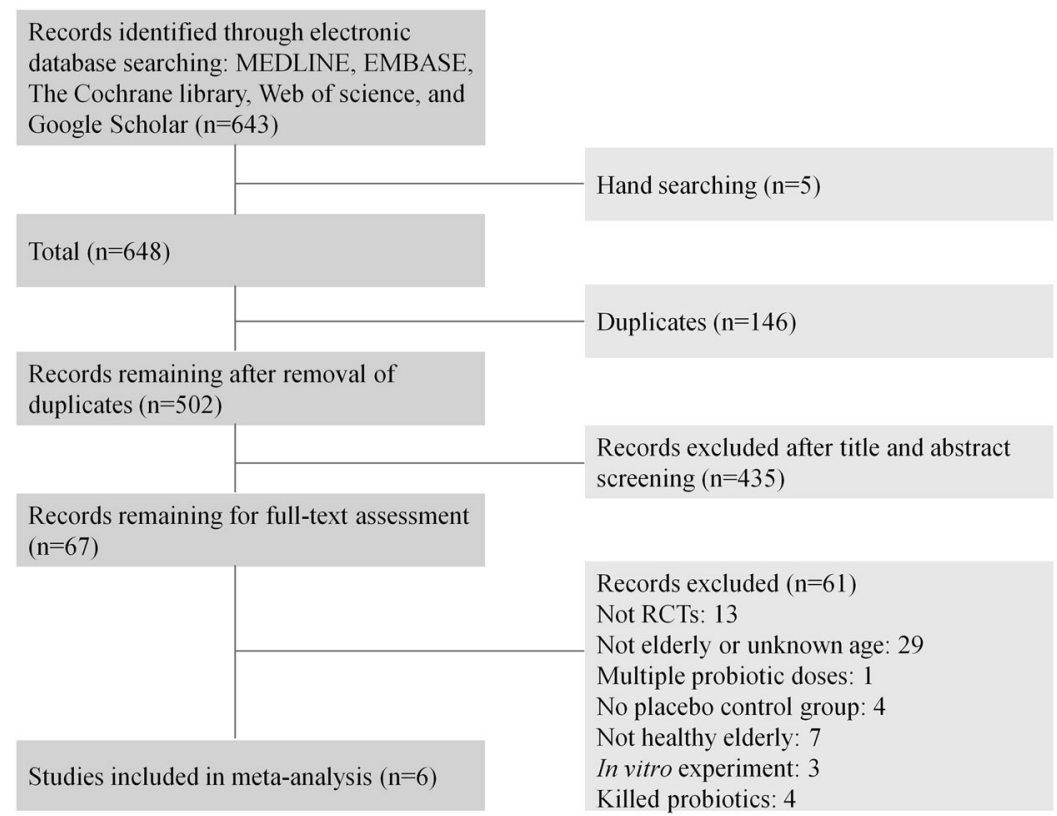

by NK cells, IFN- $\gamma$, GMCSF, MIP-1, and RANTES were reported in these RCTs; however, we could not conduct a meta-analysis of these cytokines owing to methodological heterogeneity and an insufficient number of studies.

Unlike two previously published meta-analyses [19, 20], which included prospective controlled studies (including RCTs and before-after studies) and cellular immune function (including polymorphonuclear cell phagocytic capacity and NK cell function), our meta-analysis is the first to only address RCTs and markers of NK cell function. Our decision to focus on NK cell function and RCTs was based on two major considerations. First, choosing RCTs only, and not all prospective control studies, reduces clinical confounding and bias, allowing us to obtain more convincing results for clinical outcomes. Second, NK cell function is an important component of innate immunity and plays a key role in the immune system of elderly individuals [32-34], and there was a sufficient number of RCTs published in the recent years for performing a meta-analysis [21, 27-31]. However, polymorphonuclear cell phagocytic capacity, which represents another important component of innate immunity $[4,19,20]$, is not suitable for meta-analysis as only two RCTs $[31,35]$ have been published on this subject, providing an insufficient amount of data.

Immune function decline affects the quality of life and the life span of elderly individuals. Among cells of the immune system, NK cells are separate effector lymphocytes with both cytotoxicity and cytokine-producing effector functions $[12,36]$. In humans, NK cells appear to play an essential role in viral infection, cancers, transplantation, autoimmunological disorders, and pregnancy [37]. NK cells readily produce IFN- $\gamma$ [12], but also produce other cytokines and chemokines, including GMCSF, IL-5, IL-13, MIP-1, and RANTES [23-25]. In this review, we not only determined NK cell function, but also determined the presence of cytokines and chemokines.

A decrease in the diversity and stability of gut microbiota in the elderly can influence chronic inflammation and age-related disorders [38]. Aging represents a major factor impacting the composition and activity of the gut microbiota, which is important for maintenance of good health and immune system function [39]. Finally, the stability of gut microbiota is critical to maintaining the integrity of the intestinal epithelial barrier and immunological homeostasis [39].

The relationship between gut microbiota dysbiosis and immune function decline provides a solid theoretical basis for the application of probiotics in order to slow immunosenescence. Probiotics are known to be beneficial in improving immune function in both human elderly subjects [40-43] and aging animal models [44-46]. The mechanism by which probiotics enhance NK cell function has been revealed in previous researches [47-50]. One study [49] suggested that NK cell activation is exopolysaccharidedependent, occurs via IL-18- and IL-12-mediated IFN- $\gamma$ production, and requires myeloid differentiation factor 88 . Similar results were reported by another study, where it was shown that lactic acid bacteria can elicit NK cell activities via IL-12 induction [50]. Similarly, dendritic cells play a vital role in activating NK cells $[47,48]$. In addition, direct stimulation of NK cells by probiotics has been reported [48].

Although we have not observed a change in IFN- $\gamma$ levels, significant increases in IFN- $\gamma$ after probiotic use have been 


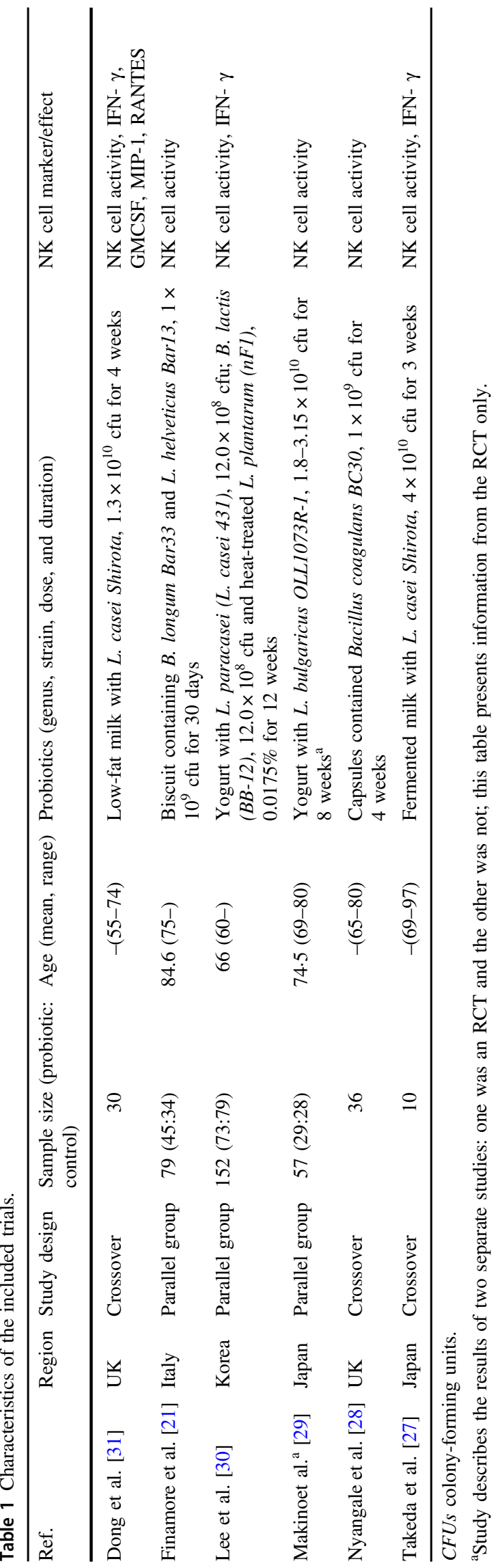

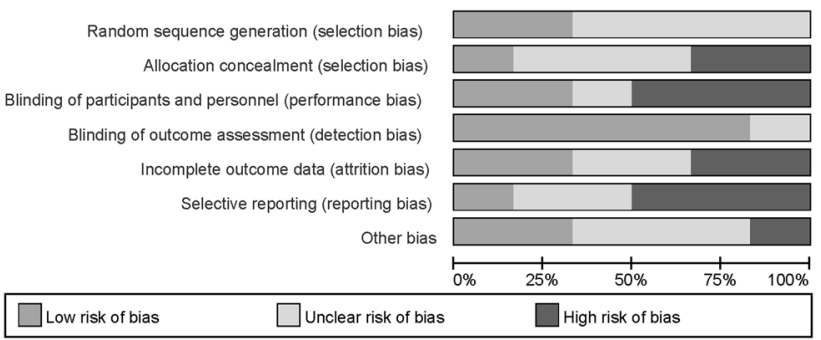

Fig. 2 Risk of bias graph representing the review authors' judgements for each risk of bias item. Data are presented as percentages across all included studies.

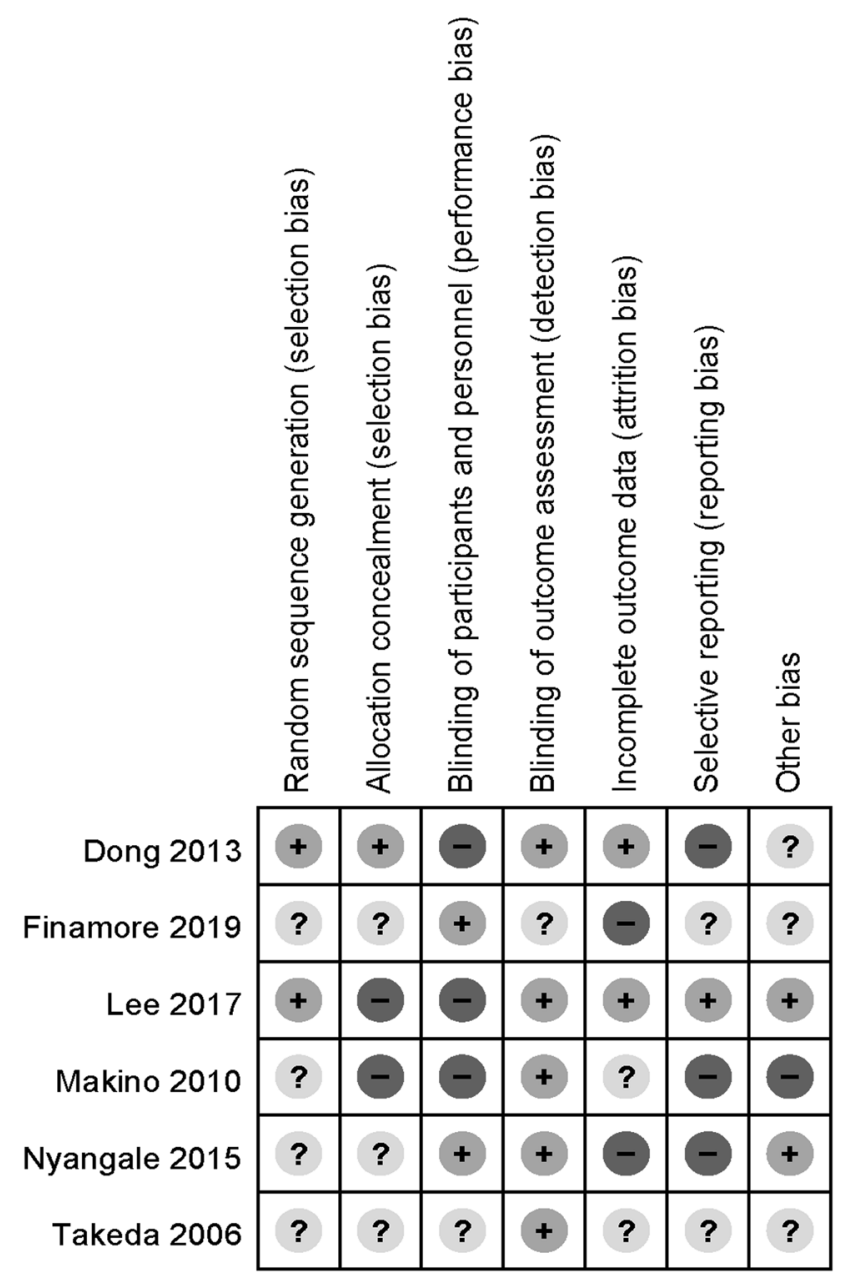

Fig. 3 Risk of bias summary. Review authors' judgements about each risk of bias item for each included study.

found in some of the articles included in our review [30, 31], which is consistent with previous studies that reported that $\mathrm{NK}$ cells secrete IFN- $\gamma$ and may represent a major source of cellular IFN- $\gamma$ [51]. The tumoricidal activity of NK cells is known to be involved in the production of IFN- $\gamma$ [52]. Therefore, an increase in IFN- $\gamma$ accompanied by an increase in NK cell tumoricidal activity after probiotic 


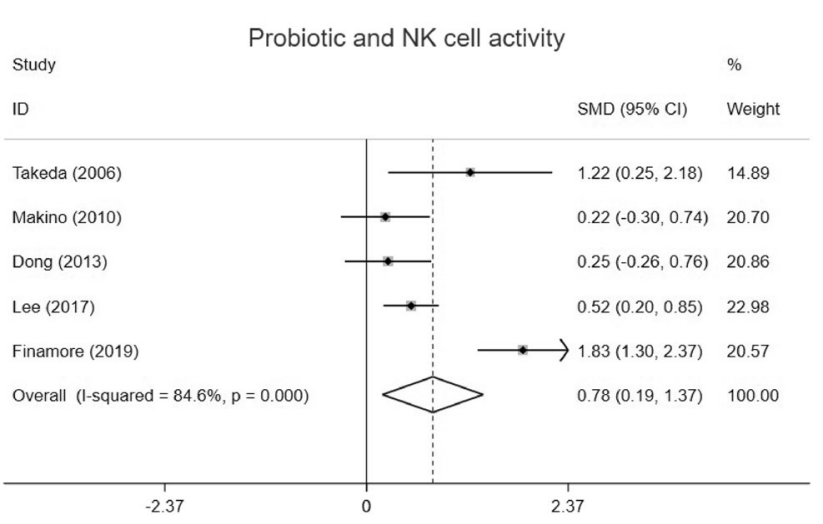

Fig. 4 Forest plot obtained after pooling data for NK cell activity from eligible studies. Random-effects meta-analysis was performed using SMD statistics. ID identification, NK cell natural killer cell, SMD standard mean difference.

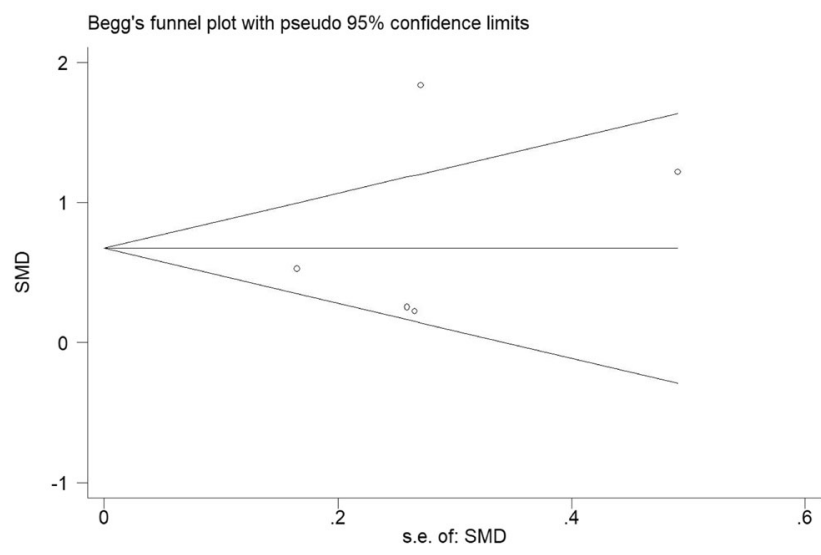

Fig. 5 Begg's funnel plot for assessment of publication bias for NK cell activity. SMD standard mean difference.

supplementation could contribute to immunopotentiation effects.

NK cells can control microbial infectious diseases $[12,53]$, and studies have shown that low NK cell activity is related to the development of infection in elderly subjects [54]. Several studies have shown that probiotics can reduce the incidence of infections in elderly subjects by augmenting NK cell activity [29] or enhancing $\mathrm{T}$ cell-mediated natural immune defense [55], although some authors disagree with this hypothesis [56, 57]. In our review, we have not discussed infections because only one study had reported on this issue [29], preventing a systematic statistical analysis. In addition, only short-term effects of probiotic applications were evaluated, and this study duration may not reveal any obvious influence on infection. For example, in a Japanese study, L. casei strain Shirota was administered to residents, staff of housing facilities, and the elderly for up to 6 months to evaluate the effectiveness in infection control, indicating the need for a long-term analysis [58].
This systematic review has several limitations. First, only six studies were included, with only five studies used to evaluate NK cell activity; this number is too small to provide robust conclusions. Second, most studies consisted of small sample sizes, which can influence the outcomes when including such studies. Third, long-term effects of probiotic use on NK cell function could not be determined in our work owing to short-term follow-ups, ranging from 3 to 12 weeks. The included studies only assessed the short-term effect of probiotic use on NK cell function, thus the longterm effects such as fighting infection and improving vaccine response could not be evaluated. Finally, probiotic strains and doses were different among the studies. For example, three probiotic interventions were primarily Lactobacillus alone, two combined Lactobacillus with Bifidobacterium, and one was primarily B. coagulans-based. A previous study has shown that the relative efficacy of probiotic supplementation may be strain-specific [59]. In addition, the doses employed were also different, ranging from $1 \times 10^{9}$ to $4 \times 10^{10} \mathrm{CFU}$. However, there were not enough studies for a subgroup meta-analysis, and we have no evidence that the effectiveness of probiotic supplementation for NK cell function in healthy elderly individuals varies according to probiotic genus and dose.

In conclusion, only RCTs were included in our metaanalysis for investigating the effect of probiotic use on $\mathrm{NK}$ cell function in healthy elderly individuals. These studies represent the highest level of evidence, according to the Cochrane Handbook. We found that short-term probiotic supplementation can in fact improve NK cell function in healthy elderly individuals. The main strength of this analysis is that it provides a compilation of the available highquality RCTs evaluating probiotic interventions in healthy elderly individuals and gives an overview of the current clinical research. Although we obtained a significant outcome, the data still do not provide convincing evidence, given the small final number of RCTs and very large heterogeneity. Future studies on a larger scale, including longterm follow-up and a multicenter investigation, are still required to establish a more robust conclusion.

Acknowledgements We thank Editage (www.editage.cn) for English language editing.

Funding The present study was supported by the National Clinical Key Specialty Construction Project of Geriatrics, the Key Disciplines Construction Plan of Zhejiang Province Traditional Chinese Medicine (2017-XK-A31), National Basic Research Program of China (973 Program; grant no. 2013CB531402), and the National Key Research and Development Program of China (2018YFC2000301, 2018YFC2000501).

Author contributions Conceptualization: YY, CX. Literature search: QG, AW. Data collection: QG, AW, ZT. Analysis and interpretation of 
data: XZ, SH. Writing—original draft: QG. Writing-review and editing: YY, CX.

\section{Compliance with ethical standards}

Conflict of interest $\mathrm{CX}$ is the first corresponding author of this work. YY is the second corresponding author of this work. All the authors reviewed and approved the submitted version of the paper. The authors declare that they have no conflict of interest.

Publisher's note Springer Nature remains neutral with regard to jurisdictional claims in published maps and institutional affiliations.

\section{References}

1. Vlasova RM, Siddarth P, Krause B, Leaver AM, Laird KT, St Cyr $\mathrm{N}$, et al. Resilience and white matter integrity in geriatric depression. Am J Geriatr Psychiatry. 2018;26:874-83. https://doi. org/10.1016/j.jagp.2018.04.004.

2. Aiello A, Farzaneh F, Candore G, Caruso C, Davinelli S, Gambino CM, et al. Immunosenescence and its hallmarks: how to oppose aging strategically? a review of potential options for therapeutic intervention. Front Immunol. 2019;10:2247. https:// doi.org/10.3389/fimmu.2019.02247.

3. Fulop T, Larbi A, Dupuis G, Le Page A, Frost EH, Cohen AA, et al. Immunosenescence and inflamm-aging as two sides of the same coin: friends or foes? Front Immunol 2017;8:1960. https:// doi.org/10.3389/fimmu.2017.01960.

4. Fuentes E, Fuentes M, Alarcon M, Palomo I. Immune system dysfunction in the elderly. Acad Bras Cienc. 2017;89:285-99. https://doi.org/10.1590/0001-3765201720160487.

5. Weyand CM, Goronzy JJ. Aging of the immune system. Mechanisms and therapeutic targets. Ann Am Thorac Soc. 2016;13:S422-8. https://doi.org/10.1513/AnnalsATS.201602-095AW.

6. Hui DS, EIA, Madani TA, Ntoumi F, Kock R, Dar O, et al. The continuing 2019-nCoV epidemic threat of novel coronaviruses to global health-the latest 2019 novel coronavirus outbreak in Wuhan, China. Int J Infect Dis. 2020;91:264-6. https://doi.org/10. 1016/j.ijid.2020.01.009.

7. Paules CI, Marston HD, Fauci AS. Coronavirus infections-more than just the common cold. JAMA. 2020. https://doi.org/10.1001/ jama.2020.0757.

8. Lu H, Stratton CW, Tang YW. Outbreak of pneumonia of unknown etiology in Wuhan, China: the mystery and the miracle. J Med Virol. 2020;92:401-2. https://doi.org/10.1002/jmv.25678.

9. Wang D, Hu B, Hu C, Zhu F, Liu X, Zhang J, et al. Clinical characteristics of 138 hospitalized patients with 2019 novel coronavirus-infected pneumonia in Wuhan, China. JAMA. 2020. https://doi.org/10.1001/jama.2020.1585.

10. Huang C, Wang Y, Li X, Ren L, Zhao J, Hu Y, et al. Clinical features of patients infected with 2019 novel coronavirus in Wuhan, China. Lancet. 2020;395:497-506. https://doi.org/10. 1016/s0140-6736(20)30183-5.

11. Solana R, Tarazona R, Gayoso I, Lesur O, Dupuis G, Fulop T. Innate immunosenescence: effect of aging on cells and receptors of the innate immune system in humans. Semin Immunol. 2012;24:331-41. https://doi.org/10.1016/j.smim.2012.04.008.

12. Vivier E, Tomasello E, Baratin M, Walzer T, Ugolini S. Functions of natural killer cells. Nat Immunol. 2008;9:503-10. https://doi. org/10.1038/ni1582.

13. Camous X, Pera A, Solana R, Larbi A. NK cells in healthy aging and age-associated diseases. J Biomed Biotechnol. 2012;2012: 195956. https://doi.org/10.1155/2012/195956.
14. Gayoso I, Sanchez-Correa B, Campos C, Alonso C, Pera A, Casado JG, et al. Immunosenescence of human natural killer cells. J Innate Immun. 2011;3:337-43. https://doi.org/10.1159/ 000328005.

15. Kamada N, Seo SU, Chen GY, Nunez G. Role of the gut microbiota in immunity and inflammatory disease. Nat Rev Immunol. 2013;13:321-35. https://doi.org/10.1038/nri3430.

16. Belkaid Y, Harrison OJ. Homeostatic immunity and the microbiota. Immunity. 2017;46:562-76. https://doi.org/10.1016/j.immuni.2017. 04.008 .

17. Guarner F, Khan AG, Garisch J, Eliakim R, Gangl A, Thomson A, et al. World gastroenterology organisation global guidelines: probiotics and prebiotics October 2011. J Clin Gastroenterol. 2012;46:468-81. https://doi.org/10.1097/MCG.0b013e3182549092.

18. Bruins MJ, Van Dael P, Eggersdorfer M. The role of nutrients in reducing the risk for noncommunicable diseases during aging. Nutrients. 2019;11. https://doi.org/10.3390/nu11010085.

19. Miller LE, Lehtoranta L, Lehtinen MJ. Short-term probiotic supplementation enhances cellular immune function in healthy elderly: systematic review and meta-analysis of controlled studies. Nutr Res. 2019;64:1-8. https://doi.org/10.1016/j.nutres.2018.12. 011.

20. Miller LE, Lehtoranta L, Lehtinen MJ. The effect of bifidobacterium animalis ssp lactis HN019 on cellular immune function in healthy elderly subjects: systematic review and meta-analysis. Nutrients. 2017;9:191. https://doi.org/10.3390/nu9030191.

21. Finamore A, Roselli M, Donini L, Brasili DE, Rami R, Carnevali $\mathrm{P}$, et al. Supplementation with bifidobacterium longum Bar33 and Lactobacillus helveticus Bar13 mixture improves immunity in elderly humans (over 75 years) and aged mice. Nutrition. 2019;63-64:184-92. https://doi.org/10.1016/j.nut.2019.02.005.

22. Moher D, Liberati A, Tetzlaff J, Altman DG. Preferred reporting items for systematic reviews and meta-analyses: the PRISMA statement. J Clin Epidemiol. 2009;62:1006-12. https://doi.org/10. 1016/j.jclinepi.2009.06.005

23. Dorner BG, Smith HR, French AR, Kim S, Poursine-Laurent J, Beckman DL, et al. Coordinate expression of cytokines and chemokines by NK cells during murine cytomegalovirus infection. J Immunol. 2004;172:3119-31. https://doi.org/10.4049/ jimmunol.172.5.3119.

24. Loza MJ, Zamai L, Azzoni L, Rosati E, Perussia B. Expression of type 1 (interferon gamma) and type 2 (interleukin-13, interleukin5) cytokines at distinct stages of natural killer cell differentiation from progenitor cells. Blood. 2002;99:1273-81. https://doi.org/10. 1182/blood.v99.4.1273.

25. Robertson MJ. Role of chemokines in the biology of natural killer cells. J Leukoc Biol. 2002;71:173-83.

26. Higgins JP, Altman DG, Gotzsche PC, Juni P, Moher D, Oxman $\mathrm{AD}$, et al. The Cochrane Collaboration's tool for assessing risk of bias in randomised trials. Bmj 2011;343:d5928. https://doi.org/10. 1136/bmj.d5928.

27. Takeda K, Suzuki T, Shimada SI, Shida K, Nanno M, Okumura $\mathrm{K}$. Interleukin-12 is involved in the enhancement of human natural killer cell activity by Lactobacillus casei Shirota. Clin Exp Immunol. 2006;146:109-15. https://doi.org/10.1111/j.1365-2249. 2006.03165.x.

28. Nyangale EP, Farmer S, Cash HA, Keller D, Chernoff D, Gibson GR. Bacillus coagulans GBI-30, 6086 modulates Faecalibacterium prausnitzii in older men and women. $\mathrm{J}$ Nutr. 2015;145:1446-52. https://doi.org/10.3945/jn.114.199802.

29. Makino S, Ikegami S, Kume A, Horiuchi H, Sasaki H, Orii N. Reducing the risk of infection in the elderly by dietary intake of yoghurt fermented with Lactobacillus delbrueckii ssp. bulgaricus OLL1073R-1. Br J Nutr. 2010;104:998-1006. https://doi.org/10. 1017/s000711451000173x. 
30. Lee A, Lee YJ, Yoo HJ, Kim M, Chang Y, Lee DS, et al. Consumption of dairy yogurt containing Lactobacillus paracasei ssp paracasei, bifidobacterium animalis ssp lactis and heat-treated Lactobacillus plantarum improves immune function including natural killer cell activity. Nutrients. 2017;9. https://doi.org/10. 3390/nu9060558.

31. Dong H, Rowland I, Thomas LV, Yaqoob P. Immunomodulatory effects of a probiotic drink containing Lactobacillus casei Shirota in healthy older volunteers. Eur J Nutr. 2013;52:1853-63. https:// doi.org/10.1007/s00394-012-0487-1.

32. Valiathan R, Ashman M, Asthana D. Effects of ageing on the immune system: infants to elderly. Scand J Immunol. 2016;83:255-66. https://doi.org/10.1111/sji.12413.

33. Kaszubowska L, Kaczor JJ, Hak L, Dettlaff-Pokora A, Szarynska M, Kmiec Z. Sensitivity of natural killer cells to activation in the process of ageing is related to the oxidative and inflammatory status of the elderly. J Physiol Pharmacol. 2011;62:101-9.

34. DiPenta JM, Johnson JG, Murphy RJ. Natural killer cells and exercise training in the elderly: a review. Can J Appl Physiol. 2004;29:419-43. https://doi.org/10.1139/h04-027.

35. Arunachalam K, Gill H, Chandra RK. Enhancement of natural immune function by dietary consumption of bifidobacterium lactis (HN019). Eur J Clin Nutr. 2000;54:263-7. https://doi.org/10. 1038/sj.ejen.1600938.

36. Vivier E, Nunès JA, Vély F. Natural killer cell signaling pathways. Science. 2004;306:1517-9. https://doi.org/10.1126/science. 1103478.

37. Orange JS, Ballas ZK. Natural killer cells in human health and disease. Clin Immunol. 2006;118:1-10. https://doi.org/10.1016/j. clim.2005.10.011.

38. Lynch SV, Pedersen O. The human intestinal microbiome in health and disease. N. Engl J Med. 2016;375:2369-79. https://doi. org/10.1056/NEJMra1600266.

39. Clements SJ. SRC diet, the intestinal microbiota, and immune health in aging. Crit Rev Food Sci Nutr. 2018;58:651-61. https:// doi.org/10.1080/10408398.2016.1211086.

40. Maruyama M, Abe R, Shimono T, Iwabuchi N, Abe F, Xiao JZ. The effects of non-viable Lactobacillus on immune function in the elderly: a randomised, double-blind, placebo-controlled study. Int J Food Sci Nutr. 2016;67:67-73. https://doi.org/10.3109/ 09637486.2015.1126564.

41. Costabile A, Bergillos-Meca T, Rasinkangas P, Korpela K, de Vos WM, Gibson GR. Effects of soluble corn fiber alone or in synbiotic combination with Lactobacillus rhamnosus GG and the pilus-deficient derivative GG-PB12 on fecal microbiota, metabolism, and markers of immune function: a randomized, doubleblind, placebo-controlled, crossover study in healthy elderly (Saimes Study). Front Immunol. 2017;8:1443. https://doi.org/10. 3389/fimmu.2017.01443.

42. Mane J, Pedrosa E, Loren V, Gassull MA, Espadaler J, Cune J, et al. A mixture of Lactobacillus plantarum CECT 7315 and CECT 7316 enhances systemic immunity in elderly subjects. A dose-response, double-blind, placebo-controlled, randomized pilot trial. Nutr Hosp. 2011;26:228-35.

43. Moro-Garcia MA, Alonso-Arias R, Baltadjieva M, Fernandez Benitez C, Fernandez Barrial MA, Diaz Ruisanchez E, et al. Oral supplementation with Lactobacillus delbrueckii subsp. bulgaricus 8481 enhances systemic immunity in elderly subjects. Age. 2013;35:1311-26. https://doi.org/10.1007/s11357-012-9434-6.

44. Sharma R, Kapila R, Kapasiya M, Saliganti V, Dass G, Kapila S. Dietary supplementation of milk fermented with probiotic Lactobacillus fermentum enhances systemic immune response and antioxidant capacity in aging mice. Nutr Res. 2014;34:968-81. https://doi.org/10.1016/j.nutres.2014.09.006.

45. Fu YR, Yi ZJ, Pei JL, Guan S. Effects of Bifidobacterium bifidum on adaptive immune senescence in aging mice. Microbiol
Immunol. 2010;54:578-83. https://doi.org/10.1111/j.1348-0421. 2010.00255.x.

46. Sharma R, Kapila R, Dass G, Kapila S. Improvement in Th1/Th2 immune homeostasis, antioxidative status and resistance to pathogenic E. coli on consumption of probiotic Lactobacillus rhamnosus fermented milk in aging mice. Age. 2014;36:9686. https://doi.org/10.1007/s11357-014-9686-4.

47. Suzuki H, Ohshio K, Fujiwara D. Lactococcus lactis subsp. lactis JCM 5805 activates natural killer cells via dendritic cells. Biosci Biotechnol Biochem. 2016;80:798-800. https://doi.org/10.1080/ 09168451.2015.1116922.

48. Rizzello V, Bonaccorsi I, Dongarra ML, Fink LN, Ferlazzo G. Role of natural killer and dendritic cell crosstalk in immunomodulation by commensal bacteria probiotics. J Biomed Biotechnol. 2011;2011:473097. https://doi.org/10.1155/2011/473097.

49. Makino S, Sato A, Goto A, Nakamura M, Ogawa M, Chiba Y, et al. Enhanced natural killer cell activation by exopolysaccharides derived from yogurt fermented with Lactobacillus delbrueckii ssp. bulgaricus OLL1073R-1. J Dairy Sci. 2016;99:915-23. https:// doi.org/10.3168/jds.2015-10376.

50. Iwabuchi N, Yonezawa S, Odamaki T, Yaeshima T, Iwatsuki K, Xiao JZ. Immunomodulating and anti-infective effects of a novel strain of Lactobacillus paracase $i$ that strongly induces interleukin12. FEMS Immunol Med Microbiol. 2012;66:230-9. https://doi. org/10.1111/j.1574-695X.2012.01003.x.

51. Heremans H, Dillen C, van Damme J, Billiau A. Essential role for natural killer cells in the lethal lipopolysaccharide-induced Shwartzman-like reaction in mice. Eur J Immunol. 1994;24:1155-60. https://doi.org/10.1002/eji.1830240522.

52. Spaggiari GM, Contini P, Negrini S, Dondero A, Carosio R, Ghio $\mathrm{M}$, et al. IFN-gamma production in human NK cells through the engagement of CD8 by soluble or surface HLA class I molecules. Eur J Immunol. 2003;33:3049-59. https://doi.org/10.1002/eji. 200323981

53. Vidal SM, Khakoo SI, Biron CA. Natural killer cell responses during viral infections: flexibility and conditioning of innate immunity by experience. Curr Opin Virol. 2011;1:497-512. https://doi.org/10.1016/j.coviro.2011.10.017.

54. Ogata K, An E, Shioi Y, Nakamura K, Luo S, Yokose N, et al. Association between natural killer cell activity and infection in immunologically normal elderly people. Clin Exp Immunol. 2001;124:392-7. https://doi.org/10.1046/j.1365-2249.2001. 01571.x.

55. Pu F, Guo Y, Li M, Zhu H, Wang S, Shen X, et al. Yogurt supplemented with probiotics can protect the healthy elderly from respiratory infections: a randomized controlled open-label trial. Clin Inter Aging. 2017;12:1223-31. https://doi.org/10.2147/cia. s141518.

56. Wang B, Hylwka T, Smieja M, Surrette M, Bowdish DME, Loeb M. Probiotics to prevent respiratory infections in nursing homes: a pilot randomized controlled trial. $\mathrm{J}$ Am Geriatr Soc. 2018;66:1346-52. https://doi.org/10.1111/jgs.15396.

57. Wachholz PA, Nunes VDS, Polachini do Valle A, Jacinto AF, Villas-Boas PJF. Effectiveness of probiotics on the occurrence of infections in older people: systematic review and meta-analysis. Age Ageing. 2018;47:527-36. https://doi.org/10.1093/ageing/a fy006.

58. Nagata S, Asahara T, Wang C, Suyama Y, Chonan O, Takano K, et al. The effectiveness of Lactobacillus beverages in controlling infections among the residents of an aged care facility: a randomized placebo-controlled double-blind trial. Ann Nutr Metab. 2016;68:51-9. https://doi.org/10.1159/000442305.

59. Guslandi M. Are probiotics effective for treating Clostridium difficile disease and antibiotic-associated diarrhea? Nat Clin Pr Gastroenterol Hepatol. 2006;3:606-7. https://doi.org/10.1038/ ncpgasthep0627. 